\title{
Learning in lockdown: A case study in rapid transition to remote teaching
}

Business Information Review

202I, Vol. 38(I) I5-20

(C) The Author(s) 2021

\section{(c) (i)}

Article reuse guidelines:

sagepub.com/journals-permissions DOI: | $0.1 \mid 77 / 0266382$ | 2098473 |

journals.sagepub.com/home/bir

(S)AGE

Jela Webb

University of Brighton, UK

\begin{abstract}
Disruption is the by-word for 2020. Across the globe organisations have been affected by the COVID-19 pandemic and consequent lockdowns, which accelerated new ways of working and learning. In this article, I share my experience of transitioning from a face-to-face model of delivering post-graduate education to a remote learning model. I reflect on how the corporate sector might learn from my experience as it considers re-skilling and up-skilling the workforce to meet the demands faced by a changing jobs landscape.
\end{abstract}

\section{Keywords}

Digital capability, e-learning, learning, remote working, skills

\section{Introduction}

The Covid-19 pandemic, within an extremely short timeframe, had a very significant effect on the nature of teaching in higher education (Walker et al., 2020). Affecting all types of educational establishments, nationally and internationally, it served to place much emphasis on institutions' ability to respond to a fast-changing environment and not least, tested their crisis management capabilities.

Contingency planning was not always in place. Where it was in place, many organisations did not have plans of sufficient focus to deal with the impact of a global pandemic (Ellis and Werdelin, 2020). While Business Schools have experts in strategy, business planning and crisis management the pandemic was uniquely challenging and it is not an exaggeration to state that the situation and responses to it were changing hourly (Ellis and Werdelin, 2020).

Within the higher education sector, short-term actions such as moving away from delivering in physical spaces to delivering remotely (using online technologies) were early indications of the first reactive phase. Initially, this was seen as a temporary 'fix'. However, as the virus continued to be in circulation, institutions came to realise that these short-term solutions were not just going to be fleeting and in essence, they started to become the foundation for medium/long term planning. It was apparent that significant levels of off campus delivery would become part of the 'new normal'.

The University of Brighton responded to the lockdown by transitioning to a remote learning model (Ellis and Werdelin, 2020; Levy, 2020). We were encouraged to use the
Five Stage Model for online learning, developed by Salmon (2002).

This case study explores how an MBA module at the University of Brighton, Business School was changed from a planned campus delivery mode to fully remote delivery mode. Additionally, it considers the longer-term implications for academia and how other businesses might learn from this experience.

\section{Transition}

The week beginning 16th March 2020 was designated as a 'transition week' with staff and students being informed that with effect from 23rd March 2020, all teaching would be delivered remotely. In the event, 24th March 2020 was the first day of 'lockdown' with the Prime Minister, Boris Johnson, announcing measures to combat the spread of the virus - 'stay home, protect the NHS, save lives'. The timing in respect of the proposed move to remote delivery was prescient. To anyone watching developments in Italy and Spain (who were ahead of the 'pandemic curve'), this instruction was not unexpected but only provided very short notice during which to implement changes to the educational experience of students

During the transition week, the in-house Learning Technology Team (who typically provided academic staff and course teams with support, guidance and advice on using

\section{Corresponding author:}

Jela Webb.

Email: jw126@brighton.ac.uk 
technologies to underpin teaching and research) worked quickly to set up a suite of online learning resources and workshops to aid staff in developing a remote delivery model. These resources included research into inclusive online learning, toolkits, case studies and online workshops on technologies to support digitally enabled learning.

\section{The module}

The post-graduate core module titled 'Managing in an Uncertain Environment' was delivered to a cohort of MBA students, most of who were combining work with study. It is a 20-credit module with summative assessments submitted six weeks after completion of the taught elements.

The module's learning outcomes were:

- To critically explore the relevance and impacts of the dynamic organisational environment in areas such as public service complexity, collaborative working, knowledge management or similar current issues.

- To produce a project, which meets both the academic criteria for post-graduate study and the expectations of employers.

- To demonstrate effective working as a member of a learning group of professionals and a wider learning community, demonstrating self-responsibility, autonomy and contribution to the professional and personal development of others as well as an ability to learn from reflection.

Assessment comprised a 4000-word report (weighting 100 per cent) and a 1000-word reflective statement (marked on a pass/fail basis).

The report required students to identify, analyse and evaluate the external environmental challenges which impact on their organisation and sector.

The report needed to cover part or all of the political, economical, sociological and technological (PEST) aspects from their study of the external environment and the challenges that it brings. The choice to cover all or part of the PEST model was for individual students to decide with the caveat that their choice should be determined by how the theories and ideas presented, applied to their organisational context.

Students were required to critically apply theories, models and concepts from the module, as they related to their particular organisational context.

Within the assessment, students were presented with the opportunity to apply theoretical models and concepts, to underpin the report, which should, in turn, be useful to their organisation and act as a learning vehicle for themselves.

The reflective statement required a subjective and personal analysis of the impact of the learning to their professional and personal development. The purpose of the reflection was to help students consolidate their learning and assist them in becoming effective reflective practitioners. A particular emphasis was to help develop reflective practice and thus encourage continuous engagement in improving personal skills as well as professional practice.

Traditionally, the module had been taught face-to-face, over a five-day block typically running for three days prior to a weekend, two days immediately after the weekend. We moved to this 'split' delivery mode a few years ago after receiving student feedback that a five-day Monday to Friday block was too intense. They indicated that they would welcome and would find it beneficial to have a weekend in between, as it would give them an opportunity to better assimilate what they were being taught.

The teaching was shared between two colleagues and me; our respective specialisms are economics and knowledge management.

\section{Planning and preparation}

With a very short notice period in terms of having to continue delivery but move it to a digital setting, we initially approached the students to ascertain what would best work for them. We were cognisant of the fact that some of the students were in full-time employment, so most were completing their studies part-time however there were also fulltime students (who were completing the MBA programme over a shorter timescale). The pandemic induced lockdown was bound to have different impacts for different students (and indeed lecturers) particularly those whose employment was in a key-worker role. Added to this, we were aware that some students would additionally have caring responsibilities, exacerbated by the pandemic and some who were having to home school their children. Another factor that needed to be borne in mind was the geographical location and time differences, as not all students were UK based.

We were aware of the fact that it would be unrealistic to try and mirror the face-to-face delivery wholly online so while we had an idea of how we could teach it, we wanted to engage students in taking some responsibility for the manner in which the module was to be delivered. We were keen for them to be partners with us, rather than passive recipients.

Students almost without exception felt that a combination of asynchronous and synchronous teaching would work best. One student did however express a very strong view that having booked five days study leave to attend the (previously scheduled) face-to-face teaching block, that synchronous online learning should follow the same pattern. He therefore argued for five full days of live online delivery. Subsequent conversations took place with that student and he was persuaded that his preference would not be feasible (five consecutive days featuring purely online classes). Screen fatigue would develop due to the 
significant reliance on such a programme of remote learning. Pleasingly, he accepted the majority view. He has subsequently been very complimentary about the delivery and engaged extremely well throughout.

We, the three-person module teaching team, reviewed the students' various preferences and were pleased that the majority view concurred with ours in that we preferred to deliver the module using a blend of asynchronous and synchronous online learning.

The module content was split into three broad areas: (1) Economics (micro and macro), (2) Political Analysis and (3) Knowledge Management.

The module content sought to explore the dynamic nature of the concept of public, private and not-for-profit services in a complex environment. Ironically, the impact of the pandemic allowed us to demonstrate, in real time, how managers could manage in an evolving and continuing period of significant uncertainty. We were 'fortunate' in the sense that what we were going to be teaching our students, could be supplemented with real life examples (from the impact the crisis was having, nationally and globally). We thus had a fortuitous opportunity to show students how this, one of the most challenging of times in the modern era, could/would impact their particular organisation.

The delivery planning was also done remotely with weekly online meetings taking place to ensure that we were going to be consistent in our approach and make use of similar online teaching tools. All three of us had had some prior experience of using an element of remote delivery in our teaching but none of us had delivered a whole module using remote learning. It was therefore a steep learning curve for us too.

The university's Blackboard Learning Management System had been in place for many years and we were familiar with that. However, it had mostly been used as a repository for study materials with only minimal use made of interactive tools (that helped facilitate remote learning). New to us all was the concept of using MS Teams, the unified online collaboration platform. Using MS Teams for our planning meetings helped us familiarise ourselves with what capabilities it had that would support the delivery of the learning content we had planned and the way it operated.

We decided that for the asynchronous learning, we would use voiced over PowerPoint presentations, recorded lectures and also provide plenty of supporting materials comprising extracts from academic texts, journal articles, press articles, videos and podcasts.

The synchronous sessions would be 'live' workshops that in the main, served to explain and build on the asynchronous content but also give the students the opportunity to ask questions, to discuss and share their experiences as well as also providing a vehicle for discussing how events, as a consequence of the pandemic, were impacting their organisations.
We felt it important to have an introductory online live session during which all three lecturers were present and a final live online session where again, all three of us were present as that was set up to discuss the summative assignment and address any questions or concerns students had about the assessment requirements and processes. Between the first and last synchronous session, we took it in turns to host the daily live online sessions.

\section{Delivery}

We considered that it would be appropriate to extend the original 5-day teaching block to 7 days but spread over a 10 -day period i.e. 2 days on, 3 days off, 5 days on. That way the students could have time to assimilate the early introductory part of the module, the microeconomic environment before moving on to consider the other topic areas. Students were in agreement with this.

All the asynchronous study materials were made available on the morning of the first day. Students therefore had access to the full programme of content from the outset and could choose a time to suit their personal schedule as and when to access the materials. The caveat being that they were required to do this prior learning, before attending the accompanying live online class.

Each day, one synchronous online live session was delivered in a two-hour block. Students logged in using MS Teams. The sessions were recorded and made available soon after completion via the Blackboard Learning Management System. This enabled any student who had not been able to attend the live session to catch up easily enough in his or her own time.

From the teaching team's perspective, adapting our teaching and learning to a very different delivery platform gave much food for thought. We were all very comfortable teaching in a physical classroom, but online teaching and learning is different and calls for a different skill set. To an extent, it is fair to say that we too were learning and recognised that it was not appropriate to try to recreate the physical classroom online. We needed to break out of our comfort zones and try new ways of teaching and engaging the students.

\section{Tools}

As mentioned, we had MS Teams as the main delivery platform, and this was supplemented by the learning management system. We were therefore able to use interactive tools such as discussion forums, (private) journals, screen sharing, collaborative documents and the chat box facility.

The offline activities (asynchronous content) helped to introduce concepts, theories and models with the online sessions used to consolidate learning. 
We thought that using a variety of content formats would help to keep students engaged and alleviate, to some extent, screen fatigue.

Having a digitally enabled learning platform enabled the university to remain open throughout lockdown and enabled us to continue to deliver our full timetable of programmes albeit in a different format from our original plan.

\section{Reflections}

The pandemic served to accelerate trends that were already developing; the impact on our pedagogy where we moved to a remote delivery learning model was in essence, fasttracked. We had had pockets of remote delivery but in the main tuition followed a more traditional face-to-face model - large lecture theatres, small seminars and workshops, reading hard copy texts, presentations, discussion and debate. Beyond the pandemic, it seems that remote teaching and learning will be an integral part of the future university.

The remote learning model means that we can offer students in different geographical locations valuable learning experiences. Fears that remote learning would somehow dilute the practice have to a large extent been unfounded and while we can't fully replicate the face-toface scenario, we have shown that we can still have an interactive and collaborative learning environment. The lack of physical contact doesn't mean that neither the students nor lecturers need to lose out. Technology plays a significant part in helping to deliver an acceptable semblance of connectedness and the providers have and continue to enhance their offerings. This applies not just to academia but the wider corporate world where MS Teams and Zoom are being used for meetings, conferences, chats and collaboration. There are other options available too, depending on people having specific digital devices and operating systems (Mac or Windows).

We found that students were quite forgiving in the sense that they know we aren't professional media presenters. Our offering is not as 'slick' as a TV programme, but we've found that as long as we were clear, at the outset, what the teaching would do, students have been appreciative of our efforts. The model whereby we make the asynchronous content available prior to the accompanying live session has been much welcomed by students. They like going into a class, knowing in advance what is going to be covered. Previously, the first exposure to the content would be in the face-to-face class so this way they have more time to prepare and consider what they personally might contribute to the discussions.

We have learned that there will be glitches with the technology from time to time and the best approach is not to get stressed about this, just accept it will happen and make the best of any such situation. It is wise to have some back up plans just in case this happens, and the reality is that we would have had various learning approaches that we could draw upon in a traditional setting so this would not be too onerous to do. In fact, we have always been encouraged to cater for students with different learning needs e.g. large print, recording lectures and alternative assessment methods.

\section{What would we do differently?}

Some students found that there was not enough time to assimilate the amount of material made available in the asynchronous content. With hindsight, we should have released the materials much sooner than on the morning of the first day - a least a week in advance so that students had a more manageable workload.

In a similar fashion, we should have made it clearer as to what was essential to read and assimilate and what could be regarded as supporting material.

Inviting guest speakers would be easy to do; we refrained from involving anyone else in the delivery, partly through a lack of confidence and partly through concerns about operability. Engaging via an online forum means any invitees do not have to travel and can join from the comfort of their home/office. We have subsequently found out that guest speakers are very willing to speak with and present to our students. We have a very wide alumni network as well as very good relationships with people in a variety of roles in the public, private and non-for-profit sectors that we could have drawn upon.

We could be more creative in making fuller use of all the interactive tools available - polls, quizzes, virtual break out rooms, collaborative documents and gamification. Understandably with this first-time remote module we played it safe and used those tools we deemed to be simpler and felt more comfortable with.

The widespread adoption of technologies to support remote learning has altered our ideas about location, purpose and value of teaching. The rapid pivot to remote learning, through the lens of the impact of the pandemic (and restrictions on movement) has taken us to a place where we are unlikely to return to the 'old model'. We must remain open-minded about this new way of working, connecting and learning.

As lockdown restrictions eased, the blended learning approach which mixes face-to-face with remote teaching became the educational model and it is likely to continue post-pandemic. The virtual world cannot replicate what happens in a face-to-face setting and while there might be cost savings to be made by carrying on virtually, it does needs to be balanced with human interaction. As a lecturer in a physical classroom, I can pick up nuances, which I cannot in a virtual class. For example, I can see which students are struggling to understand, which students need some encouragement to participate and which ones need drawing out to ask questions. I can more easily gauge 
concentration levels so that I can adapt my teaching approach as necessary. Students enjoy bouncing ideas off each other, working together physically - the camaraderie from being in a shared space is difficult to achieve in a virtual setting. Screen fatigue is very real.

\section{Implications for the corporate sector}

Organisations are having to restructure. One of the consequences of the pandemic has been the shift to remote working, which is likely to continue as businesses acknowledge how successful this has been. Many are planning to continue with this model or embrace a hybrid, which includes both home and office working. This has implications not only for the way in which organisations work but also how staff are trained.

The World Economic Forum (WEF) (2020) has highlighted what the future of work will look like - increasing levels of automation, the introduction of artificial intelligence (AI), lockdowns and economic contraction will transform tasks, jobs and skills. The WEF estimates that by 2025,85 million jobs may be displaced by a shift in the division of labour between humans and machines, while 97 million new roles will emerge. Skills gaps will be high as these 'jobs of tomorrow' are created. A digitally enabled, remote workforce is becoming a necessity and, in many instances, non-negotiable especially if organisations wish to attract and retain top talent.

Historically, when business budgets were under pressure, the training budget was one of the first to be targeted. It was not always easy to see the impact of training on the bottom line, but with the rollout of remote/digital training, data is more easily available, and the impact of training can be measured more effectively.

Since lockdown in March 2020, the corporate sector has seen a spike in employees accessing e-learning and providers have seen sizeable growth in the market (Wilson, 2020). Pre-pandemic many organisations had a push culture insofar as training was concerned - a managementdriven approach where employees were 'pushed' to attend formal training courses. Much of this type of training was not digital. Contrast that with a pull culture where the learner takes responsibility for accessing the training they need, when they need it, and you can appreciate the impact that this might have on performance. The pandemic, bringing with it, new business challenges is hastening the need for organisations to become more adept and digitally capable.

The roll out of remote/digital training programmes is being fast-tracked as the pandemic peels away at barriers and resistance that were previously in place. Some of the lessons I learned could be applicable in the corporate sector. As home working is likely to continue, businesses do need to support employees with training and development activities otherwise they may not survive in the years ahead.
Businesses who are empowering their learning and development teams to develop suitable digitally enabled training programmes demonstrate that it is a strategic priority. Employees need to be supported and content needs to be engaging and accessible in a variety of formats not least to keep screen fatigue at bay.

As the career landscape changes, businesses have already started to prioritise the up-skilling and re-skilling of the workforce. Assessing the rapidly changing conditions calls for businesses to develop a training strategy that develops employees' skills and enables organisations to prepare for the future. Remote working and learning will see more and more digital training programmes delivering content to a wide constituency of employees. Building employee skills that are critical to new business models will help organisations to respond effectively to the changes ahead and for many, time is of the essence. According to McKinsey \& Company (2020) key skill sets include:

- Expanding the ability to operate fully in a digital environment

- Developing cognitive skills to ensure that critical players can respond to the need for redesign and innovation

- Strengthen social and emotional skills to ensure effective collaboration between employees

- Building adaptability and resilience skills to thrive during a changing landscape

Adapting to a digital world is more critical then ever and e-learning has the capability to deliver quality education not only in a university setting but in business as well. For those organisations that do not have in-house e-learning capability, there are many providers who can help prepare organisations for the new work environment.

Changes were evolving before the pandemic but it has accelerated matters. Robust digital training programmes, remotely delivered learning, can help ensure that employees are prepared for the future.

\section{Declaration of conflicting interests}

The author(s) declared no potential conflicts of interest with respect to the research, authorship, and/or publication of this article.

\section{Funding}

The author(s) received no financial support for the research, authorship, and/or publication of this article.

\section{References}

Ellis S, Werdelin J (2020) Business Schools, Knowledge Management and COVID-19 - An Early Perspective. Available at: www.charterdabs.org (accessed 30 June 2020). 
Levy P (2020) Taking management education online: a 4T developmental model for education designers and developers. Organisations and People 27(1/2): 09 1-09 12.

McKinsey \& Company (2020) To emerge stronger from the COVID-19 crisis, companies should start reskilling their workforces now. Available at: www.mckinsey.com (accessed 29 November 2020).

Salmon G (2002) E-Tivities. The Key to Active Online Learning. Abingdon: Taylor and Francis.

Walker J, Brewster C, Fontinha R (2020) Consultation on the impact of Covid-19 on the working lives of business, management and economics' academics in UK 2020. Available at: www.assets.henley.ac.uk (accessed 30 June 2020).
Wilson H (2020) Long-term change or short-term fix? Digital Learning September, No: 0685, p. 3.

World Economic Forum (2020) The Future of Jobs Report 2020. Geneva: World Economic Forum.

\section{Author biography}

Jela Webb is a Senior Lecturer at the University of Brighton specialising in Information and Knowledge Management (IKM). She has many years experience in her area of interest both as a practitioner and academic. She has consulted widely in IKM and is a published author, conference presenter and academic supervisor. 